\title{
Sanitary analysis, transmission and pathogenicity of fungi associated with forage plant seeds in tropical regions of Brazil ${ }^{1}$
}

\author{
Gil Rodrigues dos Santos ${ }^{2 *}$, Paulo Henrique Tschoeke², Luciana de Godoi Silva ${ }^{3}$, \\ Marcela Cristina Agustini Carneiro da Silveira², Higor Barbosa Reis², \\ Deyvid Rocha Brito², Dalmarcia de Souza Carlos ${ }^{4}$
}

\begin{abstract}
Brazil is a major producer and exporter of beef in the world, $90 \%$ of the production is made in pasture and $85 \%$ of cultivated pastures in the country are Brachiaria sp. With a growing livestock industry in the recent years, several forage plant diseases became significant importance for causing losses in pasture productivity and quality. This study aims at quantifying the species of fungi associated with seeds and their frequency in forage plants from tropical regions of Brazil. Assays were performed considering: incidence, pathogenicity and seed-seedling transmission of fungi associated with seeds. Therefore, 28 lots of forage species seeds produced in the harvest of 2010-2011 were used. Fourteen genera of fungi associated with seeds were found, among which Bipolaris sp., Phoma sp., and Curvularia sp. had pathogenic potential. It was possible to note that Bipolaris sp., is prejudicial to forage seedlings of Brachiaria, Panicum and Crotalaria. Bipolaris sp. and Curvularia sp. have an average of seed-seedling transmission of $100 \%$ and $90 \%$, respectively.
\end{abstract}

Index terms: Brachiaria sp., Bipolaris sp., seed-seedling.

\section{Análise sanitária, transmissão e patogenicidade de fungos associados a sementes de forrageiras de regiões tropicais do Brasil}

\begin{abstract}
RESUMO - O Brasil é um grande produtor e exportador de carne bovina do mundo, $90 \%$ da produção é feita em pasto e $85 \%$ das pastagens cultivadas no país são do gênero Brachiaria. Com a intensificação da atividade pecuária nos últimos anos, várias doenças de forrageiras começaram a ter importância significativa, por causarem perdas em produtividade e qualidade de pastagens. O objetivo deste trabalho foi quantificar as espécies de fungos associados a sementes e sua frequência em plantas forrageiras oriundas de regiões tropicais do Brasil. Foram realizados ensaios abordando: incidência, patogenicidade e transmissão semente - plântula, de fungos associados a sementes. Para tanto, foram utilizados 28 lotes de sementes de espécies forrageiras produzidas na safra 2010-2011. Foram encontrados 14 gêneros de fungos associados às sementes, dentre os quais Bipolaris sp., Phoma sp., e Curvularia sp, com potencial patogênico. Concluiu-se que Bipolaris sp. é patogênico às plântulas de forrageiras de Brachiaria, Crotalaria e Panicum. Bipolaris sp. e Curvularia sp. têm taxa de transmissão média respectivamente de $100 \%$ e $90 \%$ de sementes para plântulas.
\end{abstract}

Termos para indexação: Brachiaria sp., Bipolaris sp., semente-plântula.

\section{Introduction}

Brazil is the second major producer and exporter of beef in the world, $90 \%$ of the production is made in pasture and $85 \%$ of cultivated pastures in the country are Brachiaria sp. (Ferraz and Felício, 2010). The country has increased its planted pasture area in approximately $341 \%$ from 1970

\footnotetext{
${ }^{1}$ Submitted on $08 / 25 / 2013$. Accepted for publication on $12 / 15 / 2013$. ${ }^{2}$ Departamento de Fitopatologia, Universidade Federal do Tocantins, Caixa Postal 66, 77402-970 - Gurupi, TO, Brasil.

${ }^{3}$ Universidade Federal do Tocantins, Caixa Postal 66, 77402-970 - Gurupi, TO, Brasil.
}

to 2006. Currently, it is mentioned as the largest supplier of seeds for cultivation and regeneration of pasture of the domestic market and largest exporter of tropical forage plants worldwide (Deminicis et al., 2010).

The world pressure for reduction of deforestation in Brazil and the following intensification of livestock have increased the degradation of pastures. The diseases caused

\footnotetext{
${ }^{4}$ Laboratório de Fitopatologia, Universidade Federal do Tocantins, Caixa Postal 66, 77402-970 - Gurupi, TO, Brasil.

*Corresponding author < gilrsan@uft.edu.br>
} 
by fungi that reduce the pasture quality and productivity are among the reasons for this degradation (Vechiato et al., 2010).

The use of low sanitary quality seed lots is frequent, seed lots with excessive vegetal residues, soil residues and/or seeds of other forage plants and weeds (Marchi et al., 2010).

In general, the seeds can host and transport microorganisms or pathogenic agents of all taxonomic groups, being disease carriers or not. From the ecologic point of view, these agents may be divided into groups of field organisms, with predominance of phytopathogenic species, and groups of storage organisms, with reduced number of species that damage the seeds in this stage. The fungi comprise the largest number of species associated with seeds, followed by bacteria, viruses and nematodes. Among the phytopathogenic fungi, most of them can be transmitted by the seeds of host plants (Lazarotto et al., 2010; Carvalho et al., 2011).

Mostly used in pasture in the Middle West and North regions, which are the largest producers of cattle in the country, grasses and legumes have been affected by fungal diseases, such as Brachiaria brizantha (Pyricularia grisea) (Verzignassi et al., 2012) and Pythium periilum (Rhizoctonia solani) (Duarte et al., 2007), while Panicum maximum and Stylosanthes spp. have been affected by Bipolaris sp., Curvularia sp and Phoma sp. (Marchi et al., 2010).

One way to avoid the occurrence of diseases is the development of species that are resistant to fungi or by treating the seeds, increasing the costs of implantation and pasture reconstitution. Any effective control alternative must investigate which fungi attack the seeds in specific regions (Silva et al., 2007; Senhor et al., 2009).

Unlike annual cultures, the forage plant seeds are cropped by soil sweeping and in this operation they are frequently contaminated with impurities, such as clod, pieces of plants, fungi and insects (Quadros et al., 2012). The seed health is an important factor for the establishment and maintenance of good quality tropical pastures (Marchi et al., 2010). According to Vechiato et al. (2010), in order to obtain healthy seeds, there must be the creation of a seed certification program, yet it has been difficult to create it due to the absence of researches on the seed pathology field, providing information about field health, seeds tolerance to pathogenic elements and products and techniques that are efficient for the seeds treatment.

Besides the lack of scientific information, there are no regulatory measures to satisfy the Brazilian need. The Normative Instruction n. 9 of the Ministry of Agriculture Livestock and Supply, June 2, 2005, approves rules for the production, commercialization and use of seeds; however, it does not include the health regulations. This issue is included in other rules for seeds of other vegetal species, but not for forage plants (Brasil, 2005; Brasil, 2013).

Despite the great demand for information on fungi control by forage plant seed producers and exporters, the subject has not been largely studied (Lasca et al., 2004).

With the purpose of increasing this knowledge, a health analysis was carried out aiming at quantifying the species of fungi associated with seeds and their frequency in forage plants from tropical regions of Brazil.

\section{Material and Methods}

The present study was conducted at the Phytopathology Laboratory and in greenhouses at Universidade Federal do Tocantins, campus Gurupi, from July, 2012 to March, 2013. Assays were made approaching: I - Incidence, II Pathogenicity and III - Seed-seedling transmission, of fungi associated with seeds. Therefore, 28 lots of tropical forage species seeds, produced in the harvest of 2010-2011 in different cities of the states of Bahia, Goiás, São Paulo and Tocantins, were used as shown in Table 1.

\section{Assay I-Incidence}

For this assay, the blotter test method was used, following the description in the Rules for Seed Testing - RAS (Brasil, 2009a). Seeds from each lot were submitted to the following treatments: with disinfestation of tegument (CDT) and without disinfestation of tegument (SDT). The disinfestation was made by immersion of the seeds in alcohol solution (70\%) for 30 seconds, followed by immersion in sodium hypochlorite $(2 \%)$ for two minutes and, finally, in sterilized distilled water. The seeds that were not disinfested were washed in sterile water during one minute.

The experimental design was completely randomized (DIC), with ten replications, each on a Petri plate with 40 seeds of each forage plant cultivar/species. The assay was conducted in incubation chamber at $24 \pm 2{ }^{\circ} \mathrm{C}$ of temperature and photoperiod of 12 hours during seven days (Sá et al., 2011). At the end of this period, the fungi growth was evaluated. After that, with the help of a stereomicroscope, the fungi were directly identified by the observation of structures and comparison with the specialized literature (Barnett and Hunter, 1972), or after the monosporic isolation (Camera et al., 2013) after the identification of the fungi and their incidence on each forage plant species/cultivar.

"Potentially pathogenic fungi" are those capable of causing diseases in tropical forage plants, or that, although not evident, present potential to it. The "secondary or storage fungi" are those that present lower economic importance for tropical forage plants or that may cause deterioration of seeds from these species during their storage period (Marchi et al., 2010). 
Table 1. Origin of forage plant seeds produced in tropical regions of Brazil.

\begin{tabular}{|c|c|c|}
\hline Lot & Forage species - cultivar & Geographic Origin \\
\hline 1 & B. brizantha Marandu & Aparecida do Rio Doce - GO \\
\hline 3 & B. brizantha Marandu & Quirinópolis - GO \\
\hline 7 & B. decumbens Basilisk & Quirinópolis - GO \\
\hline 9 & B. ruziziensis & Quirinópolis - GO \\
\hline 15 & B. brizantha & Quirinópolis - GO \\
\hline 17 & B. humidicola & Quirinópolis - GO \\
\hline 14 & P. maximum Massai & Quirinópolis - GO \\
\hline 12 & Sthilosanthes sp. Campo Grande & Quirinópolis - GO \\
\hline 8 & B. humidicola & Gurupi - TO \\
\hline 25 & B. brizantha MG5 & Paraíso do Tocantins - TO \\
\hline 24 & B. brizantha Piatã & Guaraí - TO \\
\hline 27 & P. maximum Mombaça & Colinas do Tocantins - TO \\
\hline 18 & B. brizantha Piatã & Araguaína - TO \\
\hline 19 & B. brizantha MG5 & Araguaína - TO \\
\hline 21 & B. brizantha Marandu & Araguaína - TO \\
\hline 20 & B. humidicola & Araguaína - TO \\
\hline 23 & P. maximum Mombaça & Araguaína - TO \\
\hline 22 & C. juncea & Araguaína - TO \\
\hline 28 & Sthilosanthes sp. Campo Grande & Araguaína - TO \\
\hline 26 & C. juncea & Araguatins - TO \\
\hline 16 & B. brizantha & Barreiras - BA \\
\hline 10 & B. ruziziensis & São Desidério - BA \\
\hline 4 & B. brizantha Marandu & São Desidério - BA \\
\hline 5 & B. brizantha Marandu & São Desidério - BA \\
\hline 2 & B. brizantha Marandu & Cosmorama - SP \\
\hline 6 & B. decumbens Basilisk & Presidente Prudente - SP \\
\hline 11 & P. maximum Massai & Cosmorama - SP \\
\hline 13 & P. maximum Massai & General Salgado - SP \\
\hline
\end{tabular}

\section{Assay II - Pathogenicity}

For this assay, the used samples were 16 isolated Bipolaris sp. and Curvularia sp. obtained from eight lots of seeds: Lot 15-B. brizantha, Lot 18-B. brizantha Piatã, Lot 2-B. brizantha Marandu, Lot 19-B. brizantha MG5, Lot 7-B. decumbens Basilisk, Lot 17-B. humidicola, Lot 10-B. ruziziensis and Lot 11-P. maximum Massai. One isolated monosporic of each fungus was obtained from all lots (Camera et al., 2013). They had their pathogenicity evaluated by means inoculating the shoot part of seedlings of the 28 forage plant lots used in this study.

The experimental design was completely randomized, with 16 treatments (fungal isolated) and 10 replication. Each replication was composed by two cells $(100 \times 100 \mathrm{~mm})$ of tray containing 10 forage plant seedlings in each cell. The seedlings were obtained by sowing disinfested seeds following the same methodology described for the incidence assay, in plastic trays containing sterilized commercial substrate. The germination evaluation of each lot was made in accordance with RAS (Brasil, 2009a).

The inoculate suspension resultant from each fungal isolated was applied five days after the seedlings emergence, in the concentration of $2 \times 10^{6}$ spores $/ \mathrm{mL}$ (Macedo and Barreto, 2007).
In order to quantify the spores, a Neubauer chamber was used, and the suspensions were prepared in fungi communities cultivated in PDA media and incubated for eight days, under temperature of $25^{\circ} \mathrm{C}$ and photoperiod of 12 hours (Sá et al., 2011). After the inoculation, the seedlings were maintained in dark humid chamber, for 72 hours and were later transferred to a greenhouse for 20 days. The symptoms were evaluated five, 10, 15 and 20 days after the inoculation. Compared to Anjos et al. (2004), the leaves with symptoms were isolated, in PDA media, after the last symptoms evaluation, 20 days after the inoculation in order to confirm Koch's principles. To satisfy the seedlings' need for nutrients, they were fertilized with urea $(5 \mathrm{~g} / \mathrm{L}) 20$ days after the emergence.

With the purpose of verifying if there is influence of spots in the Brachiaria seeds tegument during their germination, another assay was made. Thus, seeds from nineteen lots of Brachiaria, without superficial disinfestation of tegument, were separated into two groups: with spots in the tegument (CMT) and without spots in the tegument (SMT). The sowing was made on plastic trays containing sterilized sand. For each lot, 400 seeds were used, being $200 \mathrm{CMT}$ and 200 SMT. The germination evaluation of each lot was made in accordance with RAS (Brasil, 2009a). 
Assay III - Seed-seedling transmission

For the seed-seedling transmission assay, 100 seeds in four replications, totalizing 400 seeds from each lot of forage plant seeds, were sowed without disinfestations of tegument, on two plastic trays/lots, containing autoclaved sand (subsoil, $40 \mathrm{~cm}$ ). After the sowing, the trays were transferred to a greenhouse and irrigated with sterilized water on a daily basis. The seedlings evaluation was made 5, 10, 15 and 20 days after the emergence by observation of the characteristic symptoms. For confirmation of Koch's principles, leaf fragments that presented symptoms were isolated in PDA media. The seedlings emergence and the incidence of unhealthy seeds were evaluated and, then, the percentage of seedlings with leaf spots in relation with seedlings without leaf spots was evaluated.

The statistical procedures were held with Sisvar software. The multiple comparisons between the averages were made by Scott-knott and/or Tukey's test at $5 \%$ of probability.

\section{Results and Discussion}

\section{Transportation of fungi associated with forage plant seeds}

As seen in Table 2, fourteen genres of fungi were detected in this assay. In the treatment without disinfestation of tegument (SDT), the saprophytic fungus Fusarium sp., was more frequent (89.3\%), followed by the potentially pathogenic fungi Curvularia sp. (75.1\%), Bipolaris sp. (67.9\%), Phoma sp. (67.9\%) and Sclerotium sp. (28.6\%). However, in the treatment with disinfestation of tegument (CDT) these fungi presented frequency of $39.3 \%, 46.4 \%, 39.3 \% ; 39.3 \%$ and $28.6 \%$ respectively. A relevant difference between the treatments SDT and CDT in the incidence of fungi Bipolaris sp., Fusarium sp., Penicillium sp., Phoma sp., Rhizophus sp. was observed (Table 2). The difference shows that fungus inoculum was adhered to the seed tegument, yet the frequency and incidence of fungi in the treatment CDT, even in lower percentage, indicate that these fungi are present on the surface, as well as on the tegument tissue of tropical forage plant seeds.

The presence of fungi on vegetal tissues was also reported by Yago et al., (2011) who studied sorghum and foxtail millet seeds and identified Curvularia sp. on the seeds' endosperm and Alternaria and Fusarium on the seeds' endosperm and embryo.

Two fungi with greatest incidence in the treatment SDT were Fusarium sp. (saprophytic) and Phoma sp. (pathogenic). For genre Fusarium sp., the largest incidence was in Brachiaria humidicola while Phoma sp. had greater incidence on $B$. brizantha Marandu, B. brizantha MG5, P. maximum Mombaça, B. ruziziensis, B. decumbens Basilisk. The other fungi has low incidence $(<10 \%)$ (Table 3 e Table 4$)$. The fungi incidence diverged among the lots when the treatment was SDT (Table 4), but not when treatment was CDT (Table 5).

Table 2. Frequency and incidence of fungi after treatment in forage plant seeds produced in tropical regions of Brazil.

\begin{tabular}{|c|c|c|c|c|}
\hline \multirow{2}{*}{ Fungus } & \multicolumn{2}{|c|}{ Frequency $(\%)$} & \multicolumn{2}{|c|}{ Incidence $(\%)$} \\
\hline & SDT* & $\mathrm{CDT}^{* *}$ & SDT $^{*}$ & $\mathrm{CDT}^{* *}$ \\
\hline Aspergillus niger & $3.6 \mathrm{a}$ & $3.6 \mathrm{a}$ & $0.5 \mathrm{a}$ & $0.03 \mathrm{a}$ \\
\hline Aspergillus sp. & $64.3 \mathrm{a}$ & $21.4 \mathrm{a}$ & $4.21 \mathrm{a}$ & $0.5 \mathrm{a}$ \\
\hline Bipolaris sp. & $67.9 \mathrm{a}$ & $39.3 \mathrm{a}$ & $4.35 \mathrm{a}$ & $0.53 b$ \\
\hline Botrytis sp. & $17.9 \mathrm{a}$ & $10.7 \mathrm{a}$ & $0.42 \mathrm{a}$ & $0.07 \mathrm{a}$ \\
\hline Chaetomium sp. & $21.4 \mathrm{a}$ & $17.9 \mathrm{a}$ & $0.92 \mathrm{a}$ & $0.35 \mathrm{a}$ \\
\hline Curvularia sp. & $75.14 \mathrm{a}$ & $46.4 \mathrm{a}$ & $3.71 \mathrm{a}$ & $0.57 \mathrm{a}$ \\
\hline Fusarium sp. & $89.3 \mathrm{a}$ & $39.3 \mathrm{a}$ & $21.82 \mathrm{a}$ & $0.42 b$ \\
\hline Helminthosporium sp. & $3.6 \mathrm{a}$ & $0 \mathrm{a}$ & $0.35 \mathrm{a}$ & $0 \mathrm{a}$ \\
\hline Penicillium sp. & $71.4 \mathrm{a}$ & $10.7 \mathrm{a}$ & $6.21 \mathrm{a}$ & $0.21 b$ \\
\hline Phoma sp. & $67.9 \mathrm{a}$ & $39.3 \mathrm{a}$ & $13.89 \mathrm{a}$ & $0.71 b$ \\
\hline Pithomyces sp. & 7.1a & $3.6 \mathrm{a}$ & $0.5 \mathrm{a}$ & $0.03 \mathrm{a}$ \\
\hline Rhizophus sp. & $46.4 \mathrm{a}$ & $10.7 \mathrm{a}$ & $6.53 \mathrm{a}$ & $0.1 \mathrm{~b}$ \\
\hline Sclerotium sp. & $28.6 \mathrm{a}$ & $28.6 \mathrm{a}$ & $0.89 \mathrm{a}$ & $0.67 \mathrm{a}$ \\
\hline Trichoderma sp. & $14.3 \mathrm{a}$ & $3.6 \mathrm{a}$ & $0.25 \mathrm{a}$ & $0.03 \mathrm{a}$ \\
\hline
\end{tabular}

*SDT - Without Disinfestation of the Tegument.

**CDT - With Disinfestation of the Tegument.

Measures followed by the same letter in the line do not differ inwardly by Tukey's test $(p<0,05)$. Analysis made between both treatments: SDT and CDT.

The incidence of fungi in seeds can happen in the field, during the storage or after the harvest, and it interferes negatively with their physiological potential (Gama et al., 2012). Saprophytic fungi, such as Fusarium sp., which are storage fungi, are capable of affecting the seeds viability, the seedlings emerged and may even kill the seedlings (Vechiato et al., 2010). The presence of storage fungi associated with the seeds is related with the harvest and post-harvest methods, as well as with the relative air humidity during storage (Lacerda et al., 2003).

The presence of fungi Aspergillus sp., Rhizopus sp., Bipolaris sp., Fusarium sp. and Phoma sp. had already been reported in seeds of $P$. maximum Massai, Mombaça and Tanzania and Stylosanthes Campo Grande (S. capitata e $S$. macrocephala), even under extremely clean physical conditions (Marchi et al., 2010). The fungi Phoma sp. and Fusarium sp. were also found in Brachiaria seeds (Lasca et al., 2004).

It is important to note that genre Rhizopus sp., Penicillium sp. and Aspergillus sp. harmed the seeds physiological quality, reducing their germination capacity (Vechiato et al., 2010), therefore, even though their incidence was not large in this study, they may represent future damages to cultivation. 
Table 3. Incidence average of fungi in tropical forage plant seeds, without disinfestation of tegument (lots average).

\begin{tabular}{|c|c|c|c|c|c|c|c|c|c|c|c|c|c|c|c|}
\hline \multirow{2}{*}{ Forage plant } & \multicolumn{14}{|c|}{ Incidence of Fungi (\%) } & \multirow{2}{*}{ Total } \\
\hline & An & As & $\mathrm{Bi}$ & Bo & $\mathrm{Ch}$ & $\mathrm{Cu}$ & $\mathrm{Fu}$ & $\mathrm{He}$ & $\mathrm{Pe}$ & $\mathrm{Ph}$ & $\mathrm{Pi}$ & $\mathrm{Rh}$ & $\mathrm{Sc}$ & $\operatorname{Tr}$ & \\
\hline B. brizantha & $0.0 \mathrm{a}$ & $5.5 \mathrm{a}$ & $3.0 \mathrm{a}$ & $0.0 \mathrm{a}$ & $2.0 \mathrm{a}$ & $5.5 \mathrm{a}$ & $19.0 \mathrm{c}$ & $0.0 \mathrm{a}$ & $6.5 \mathrm{a}$ & $6.0 \mathrm{~b}$ & $6.0 \mathrm{a}$ & $14.5 \mathrm{a}$ & $3.5 \mathrm{a}$ & $1.0 \mathrm{a}$ & 72.5 \\
\hline B. brizantha Marandu & $2.3 \mathrm{a}$ & $2.3 \mathrm{a}$ & $6.3 \mathrm{a}$ & $0.2 \mathrm{a}$ & $3.5 \mathrm{a}$ & $5.2 \mathrm{a}$ & $26.5 b$ & $0.0 \mathrm{a}$ & $2.2 \mathrm{a}$ & $31.8 \mathrm{a}$ & $0.0 \mathrm{a}$ & $7.5 \mathrm{a}$ & $1.8 \mathrm{a}$ & $0.0 \mathrm{a}$ & 89.7 \\
\hline B. brizantha MG5 & $0.0 \mathrm{a}$ & $3.0 \mathrm{a}$ & $13.5 \mathrm{a}$ & $0.0 \mathrm{a}$ & $0.0 \mathrm{a}$ & $13.5 \mathrm{a}$ & $13.5 \mathrm{c}$ & $0.0 \mathrm{a}$ & $17.0 \mathrm{a}$ & $24.5 \mathrm{a}$ & $0.0 \mathrm{a}$ & $2.5 \mathrm{a}$ & $2.0 \mathrm{a}$ & $0.0 \mathrm{a}$ & 89.5 \\
\hline B. brizantha Piatã & $0.0 \mathrm{a}$ & $9.0 \mathrm{a}$ & $4.0 \mathrm{a}$ & $0.0 \mathrm{a}$ & $0.0 \mathrm{a}$ & $0.5 \mathrm{a}$ & $34.0 \mathrm{~b}$ & $0.0 \mathrm{a}$ & $12.5 \mathrm{a}$ & $0.0 \mathrm{~b}$ & $0.0 \mathrm{a}$ & $0.0 \mathrm{a}$ & $1.5 \mathrm{a}$ & $0.0 \mathrm{a}$ & 61.5 \\
\hline B. decumbens Basilisk & $0.0 \mathrm{a}$ & $0.5 \mathrm{a}$ & $3.0 \mathrm{a}$ & $4.0 \mathrm{a}$ & $0.0 \mathrm{a}$ & $3.0 \mathrm{a}$ & $26.0 \mathrm{~b}$ & $0.0 \mathrm{a}$ & $0.5 \mathrm{a}$ & $18.0 \mathrm{a}$ & $0.0 \mathrm{a}$ & $0.0 \mathrm{a}$ & $0.0 \mathrm{a}$ & $2.0 \mathrm{a}$ & 57.0 \\
\hline B. humidicola & $0.0 \mathrm{a}$ & $0.0 \mathrm{a}$ & $5.0 \mathrm{a}$ & $0.0 \mathrm{a}$ & $0.0 \mathrm{a}$ & $4.0 \mathrm{a}$ & $55.0 \mathrm{a}$ & $0.0 \mathrm{a}$ & $0.0 \mathrm{a}$ & $1.0 \mathrm{~b}$ & $0.0 \mathrm{a}$ & $4.7 \mathrm{a}$ & $0.0 \mathrm{a}$ & $0.0 \mathrm{a}$ & 69.7 \\
\hline B. ruziziensis & $0.0 \mathrm{a}$ & $1.0 \mathrm{a}$ & $9.5 \mathrm{a}$ & $1.5 \mathrm{a}$ & $0.0 \mathrm{a}$ & $1.5 \mathrm{a}$ & $14.5 \mathrm{c}$ & $0.0 \mathrm{a}$ & $2.5 \mathrm{a}$ & $18.5 \mathrm{a}$ & $1.0 \mathrm{a}$ & $23.5 \mathrm{a}$ & $0.0 \mathrm{a}$ & $0.5 \mathrm{a}$ & 74.0 \\
\hline C. juncea & $0.0 \mathrm{a}$ & $9.5 \mathrm{a}$ & $0.0 \mathrm{a}$ & $0.0 \mathrm{a}$ & $0.0 \mathrm{a}$ & $0.0 \mathrm{a}$ & $5.0 \mathrm{c}$ & $0.0 \mathrm{a}$ & $27.0 \mathrm{a}$ & $0.0 \mathrm{~b}$ & $0.0 \mathrm{a}$ & $0.0 \mathrm{a}$ & $0.0 \mathrm{a}$ & $0.0 \mathrm{a}$ & 41.5 \\
\hline P. maximum Mombaça & $0.0 \mathrm{a}$ & $2.5 \mathrm{a}$ & $0.0 \mathrm{a}$ & $0.0 \mathrm{a}$ & $0.0 \mathrm{a}$ & $3.0 \mathrm{a}$ & $8.5 \mathrm{c}$ & $0.5 \mathrm{a}$ & $1.5 \mathrm{a}$ & $22.5 \mathrm{a}$ & $0.0 \mathrm{a}$ & $8.5 \mathrm{a}$ & $0.0 \mathrm{a}$ & $0.0 \mathrm{a}$ & 47.0 \\
\hline P. maximum Massai & $0.0 \mathrm{a}$ & $8.0 \mathrm{a}$ & $1.0 \mathrm{a}$ & $0.0 \mathrm{a}$ & $0.3 \mathrm{a}$ & $2.3 \mathrm{a}$ & $15.3 \mathrm{c}$ & $0.0 \mathrm{a}$ & $5.0 \mathrm{a}$ & $5.3 b$ & $0.0 \mathrm{a}$ & $8.7 \mathrm{a}$ & $0.0 \mathrm{a}$ & $0.0 \mathrm{a}$ & 46.0 \\
\hline Sthilosanthes sp. & $0.0 \mathrm{a}$ & $8.8 \mathrm{a}$ & $0.0 \mathrm{a}$ & $0.0 \mathrm{a}$ & $0.0 \mathrm{a}$ & $0.0 \mathrm{a}$ & $0.0 \mathrm{c}$ & $0.0 \mathrm{a}$ & $5.3 \mathrm{a}$ & $0.0 \mathrm{~b}$ & $0.0 \mathrm{a}$ & $0.0 \mathrm{a}$ & $0.0 \mathrm{a}$ & $0.0 \mathrm{a}$ & 0.0 \\
\hline Média & 0.2 & 4.6 & 4.1 & 0.5 & 0.5 & 3.5 & 19.8 & 0.0 & 7.3 & 11.6 & 0.6 & 6.3 & 0.8 & 0.3 & 58.9 \\
\hline
\end{tabular}

An: Aspergillus niger; As: Aspergillus sp.; Bi: Bipolaris sp.; Bo: Botrytis sp.; Ch: Chaetomium sp.; Cu: Curvularia sp.; Fu: Fusarium sp.; He: Helminthosporium sp.; Pe: Penicillium sp.; Ph: Phoma sp.; Pi: Pithomyces sp.; Rh: Rhizophus sp.; Sc: Sclerotium sp.; Tr: Trichoderma sp.

Measures followed by the same letter in the column do not differ inwardly by the Scott-knott's test $(\mathrm{p}<0.05)$.

Table 4. Incidence of fungi in tropical forage plant seeds, without disinfestation of tegument.

\begin{tabular}{|c|c|c|c|c|c|c|c|c|c|c|c|c|c|c|c|c|}
\hline \multirow{2}{*}{ Forage plant } & \multirow{2}{*}{ Lot } & \multicolumn{14}{|c|}{ Incidence of Fungi (\%) } & \multirow{2}{*}{ Total } \\
\hline & & An & As & $\mathrm{Bi}$ & Bo & $\mathrm{Ch}$ & $\mathrm{Cu}$ & $\mathrm{Fu}$ & $\mathrm{He}$ & $\mathrm{Pe}$ & $\mathrm{Ph}$ & $\mathrm{Pi}$ & $\mathrm{Rh}$ & $\mathrm{Sc}$ & $\operatorname{Tr}$ & \\
\hline \multirow{2}{*}{ B. brizantha } & 16 & $0 \mathrm{a}$ & $5 a$ & $3 a$ & $0 \mathrm{a}$ & $2 \mathrm{a}$ & $3 a$ & $21 \mathrm{a}$ & $0 \mathrm{a}$ & $5 a$ & $8 \mathrm{a}$ & $0 \mathrm{a}$ & $29 a$ & $5 \mathrm{a}$ & $0 \mathrm{a}$ & 81 \\
\hline & 15 & $0 \mathrm{a}$ & $6 a$ & $3 a$ & $0 \mathrm{a}$ & $2 \mathrm{a}$ & $8 \mathrm{a}$ & $17 \mathrm{a}$ & $0 \mathrm{a}$ & $8 \mathrm{a}$ & $4 a$ & $12 \mathrm{a}$ & $0 \mathrm{~b}$ & $2 \mathrm{a}$ & $2 \mathrm{a}$ & 64 \\
\hline \multirow{6}{*}{$\begin{array}{l}\text { B. brizantha } \\
\text { Marandu }\end{array}$} & 1 & $0 \mathrm{a}$ & $0 \mathrm{a}$ & $4 \mathrm{a}$ & $0 \mathrm{a}$ & $0 \mathrm{a}$ & $6 a$ & $23 a$ & $0 \mathrm{a}$ & $3 a$ & $66 a$ & $0 \mathrm{a}$ & $13 a$ & $2 \mathrm{a}$ & $0 \mathrm{a}$ & 117 \\
\hline & 21 & $14 \mathrm{a}$ & $3 a$ & $4 a$ & 0a & $0 \mathrm{a}$ & $3 a$ & $48 \mathrm{a}$ & $0 \mathrm{a}$ & $1 \mathrm{a}$ & $15 \mathrm{a}$ & $0 \mathrm{a}$ & $26 \mathrm{a}$ & $0 \mathrm{a}$ & $0 \mathrm{a}$ & 114 \\
\hline & 2 & $0 \mathrm{a}$ & $2 \mathrm{a}$ & $10 \mathrm{a}$ & $0 \mathrm{a}$ & $0 \mathrm{a}$ & $11 \mathrm{a}$ & $33 a$ & $0 \mathrm{a}$ & $5 \mathrm{a}$ & $45 \mathrm{a}$ & $0 \mathrm{a}$ & $4 a$ & $0 \mathrm{a}$ & $0 \mathrm{a}$ & 110 \\
\hline & 3 & $0 \mathrm{a}$ & $3 a$ & $4 a$ & $0 \mathrm{a}$ & $3 a$ & $7 \mathrm{a}$ & $22 a$ & $0 \mathrm{a}$ & $1 \mathrm{a}$ & $33 a$ & $0 \mathrm{a}$ & $2 \mathrm{a}$ & $5 \mathrm{a}$ & $0 \mathrm{a}$ & 80 \\
\hline & 4 & $0 \mathrm{a}$ & $6 a$ & $3 a$ & $0 \mathrm{a}$ & $8 \mathrm{a}$ & $0 \mathrm{a}$ & $11 \mathrm{a}$ & $0 \mathrm{a}$ & $2 \mathrm{a}$ & $7 \mathrm{a}$ & $0 \mathrm{a}$ & $0 \mathrm{a}$ & $3 a$ & $0 \mathrm{a}$ & 40 \\
\hline & 5 & $0 \mathrm{a}$ & $0 \mathrm{a}$ & $13 a$ & $1 \mathrm{a}$ & $10 \mathrm{a}$ & $4 a$ & $22 a$ & $0 \mathrm{a}$ & $1 \mathrm{a}$ & $25 \mathrm{a}$ & $0 \mathrm{a}$ & $0 \mathrm{a}$ & $1 \mathrm{a}$ & $0 \mathrm{a}$ & 77 \\
\hline \multirow{2}{*}{$\begin{array}{l}\text { B. brizantha } \\
\text { MG5 }\end{array}$} & 19 & $0 \mathrm{a}$ & $0 \mathrm{~b}$ & $16 \mathrm{a}$ & $0 \mathrm{a}$ & $0 \mathrm{a}$ & $5 b$ & $22 a$ & $0 \mathrm{a}$ & $0 \mathrm{~b}$ & $11 \mathrm{~b}$ & $0 \mathrm{a}$ & $5 a$ & $4 a$ & $0 \mathrm{a}$ & 63 \\
\hline & 25 & $0 \mathrm{a}$ & $6 \mathrm{a}$ & $11 \mathrm{~b}$ & $0 \mathrm{a}$ & $0 \mathrm{a}$ & $22 a$ & $5 b$ & $0 \mathrm{a}$ & $34 \mathrm{a}$ & $38 \mathrm{a}$ & $0 \mathrm{a}$ & $0 \mathrm{~b}$ & $\mathrm{Ob}$ & $0 \mathrm{a}$ & 116 \\
\hline \multirow{2}{*}{$\begin{array}{l}\text { B. brizantha } \\
\text { Piatã }\end{array}$} & 18 & $0 \mathrm{a}$ & $1 \mathrm{a}$ & $2 a$ & $0 \mathrm{a}$ & $0 \mathrm{a}$ & $1 \mathrm{a}$ & $65 a$ & $0 \mathrm{a}$ & $0 \mathrm{a}$ & $0 \mathrm{a}$ & $0 \mathrm{a}$ & $0 \mathrm{a}$ & $3 a$ & $0 \mathrm{a}$ & 72 \\
\hline & 24 & $0 \mathrm{a}$ & $17 \mathrm{a}$ & $6 a$ & $0 \mathrm{a}$ & $0 \mathrm{a}$ & $0 \mathrm{a}$ & $3 a$ & $0 \mathrm{a}$ & $25 \mathrm{a}$ & $0 \mathrm{a}$ & $0 \mathrm{a}$ & $0 \mathrm{a}$ & $0 \mathrm{a}$ & $0 \mathrm{a}$ & 51 \\
\hline \multirow{2}{*}{$\begin{array}{l}\text { B. decumbens } \\
\text { Basilisk }\end{array}$} & 6 & $0 \mathrm{a}$ & $0 \mathrm{a}$ & $2 a$ & $5 a$ & $0 \mathrm{a}$ & $3 a$ & $24 a$ & $0 \mathrm{a}$ & $0 \mathrm{a}$ & $19 \mathrm{a}$ & $0 \mathrm{a}$ & $0 \mathrm{a}$ & $0 \mathrm{a}$ & $1 \mathrm{a}$ & 54 \\
\hline & 7 & $0 \mathrm{a}$ & $1 \mathrm{a}$ & $4 a$ & $3 a$ & $0 \mathrm{a}$ & $3 a$ & $28 \mathrm{a}$ & $0 \mathrm{a}$ & $1 \mathrm{a}$ & $17 \mathrm{a}$ & $0 \mathrm{a}$ & $0 \mathrm{a}$ & $0 \mathrm{a}$ & $3 a$ & 60 \\
\hline \multirow{3}{*}{ B. humidicola } & 20 & $0 \mathrm{a}$ & $0 \mathrm{a}$ & $0 \mathrm{a}$ & $0 \mathrm{a}$ & $0 \mathrm{a}$ & $1 \mathrm{a}$ & $93 a$ & $0 \mathrm{a}$ & $0 \mathrm{a}$ & $0 \mathrm{a}$ & $0 \mathrm{a}$ & $3 a$ & $0 \mathrm{a}$ & $0 \mathrm{a}$ & 97 \\
\hline & 8 & $0 \mathrm{a}$ & $0 \mathrm{a}$ & $4 a$ & $0 \mathrm{a}$ & $0 \mathrm{a}$ & $9 \mathrm{a}$ & $23 a$ & $0 \mathrm{a}$ & $0 \mathrm{a}$ & $3 a$ & $0 \mathrm{a}$ & $0 \mathrm{a}$ & $0 \mathrm{a}$ & $0 \mathrm{a}$ & 39 \\
\hline & 17 & $0 \mathrm{a}$ & $0 \mathrm{a}$ & $11 \mathrm{a}$ & $0 \mathrm{a}$ & $0 \mathrm{a}$ & $2 \mathrm{a}$ & $49 a$ & $0 \mathrm{a}$ & $0 \mathrm{a}$ & $0 \mathrm{a}$ & $0 \mathrm{a}$ & $11 \mathrm{a}$ & $0 \mathrm{a}$ & $0 \mathrm{a}$ & 73 \\
\hline \multirow{2}{*}{ B. ruziziensis } & 9 & $0 \mathrm{a}$ & $2 a$ & $4 a$ & $2 \mathrm{a}$ & $0 \mathrm{a}$ & $2 a$ & $14 \mathrm{a}$ & $0 \mathrm{a}$ & $2 a$ & $4 a$ & $2 a$ & $42 a$ & $0 \mathrm{a}$ & $0 \mathrm{a}$ & 74 \\
\hline & 10 & $0 \mathrm{a}$ & $0 \mathrm{a}$ & $15 \mathrm{a}$ & $1 \mathrm{a}$ & $0 \mathrm{a}$ & $1 \mathrm{a}$ & $15 \mathrm{a}$ & $0 \mathrm{a}$ & $3 a$ & $33 a$ & $0 \mathrm{a}$ & $5 b$ & $0 \mathrm{a}$ & $1 \mathrm{a}$ & 74 \\
\hline \multirow{2}{*}{ C. juncea } & 22 & $0 \mathrm{a}$ & $17 \mathrm{a}$ & $0 \mathrm{a}$ & $0 \mathrm{a}$ & $0 \mathrm{a}$ & $0 \mathrm{a}$ & $0 \mathrm{~b}$ & $0 \mathrm{a}$ & $48 \mathrm{a}$ & $0 \mathrm{a}$ & $0 \mathrm{a}$ & $0 \mathrm{a}$ & $0 \mathrm{a}$ & $0 \mathrm{a}$ & 65 \\
\hline & 26 & $0 \mathrm{a}$ & $2 b$ & $0 \mathrm{a}$ & $0 \mathrm{a}$ & $0 \mathrm{a}$ & $0 \mathrm{a}$ & $10 \mathrm{a}$ & $0 \mathrm{a}$ & $6 \mathrm{~b}$ & $0 \mathrm{a}$ & $0 \mathrm{a}$ & $0 \mathrm{a}$ & $0 \mathrm{a}$ & $0 \mathrm{a}$ & 18 \\
\hline \multirow{2}{*}{$\begin{array}{l}\text { P. maximum } \\
\text { Mombaça }\end{array}$} & 23 & $0 \mathrm{a}$ & $0 \mathrm{a}$ & $0 \mathrm{a}$ & $0 \mathrm{a}$ & $0 \mathrm{a}$ & 1a & $15 \mathrm{a}$ & 1a & $0 \mathrm{a}$ & $16 \mathrm{a}$ & $0 \mathrm{a}$ & $17 \mathrm{a}$ & $0 \mathrm{a}$ & $0 \mathrm{a}$ & 50 \\
\hline & 27 & $0 \mathrm{a}$ & $5 \mathrm{a}$ & $0 \mathrm{a}$ & $0 \mathrm{a}$ & $0 \mathrm{a}$ & $5 \mathrm{a}$ & $2 \mathrm{a}$ & $0 \mathrm{a}$ & $3 a$ & $29 a$ & $0 \mathrm{a}$ & $0 \mathrm{a}$ & $0 \mathrm{a}$ & $0 \mathrm{a}$ & 44 \\
\hline \multirow{3}{*}{$\begin{array}{l}P . \text { maximum }_{\text {Massai }} \\
\text { Masain }\end{array}$} & 11 & $0 \mathrm{a}$ & $5 a$ & $3 a$ & $0 \mathrm{a}$ & $1 \mathrm{a}$ & $5 a$ & $20 \mathrm{a}$ & $0 \mathrm{a}$ & $1 \mathrm{a}$ & $11 \mathrm{a}$ & $0 \mathrm{a}$ & $0 \mathrm{a}$ & $0 \mathrm{a}$ & $0 \mathrm{a}$ & 46 \\
\hline & 13 & $0 \mathrm{a}$ & $12 \mathrm{a}$ & $0 \mathrm{a}$ & $0 \mathrm{a}$ & $0 \mathrm{a}$ & $2 \mathrm{a}$ & $19 a$ & $0 \mathrm{a}$ & $5 \mathrm{a}$ & $5 \mathrm{a}$ & $0 \mathrm{a}$ & $2 \mathrm{a}$ & $0 \mathrm{a}$ & $0 \mathrm{a}$ & 45 \\
\hline & 14 & $0 \mathrm{a}$ & $7 \mathrm{a}$ & $0 \mathrm{a}$ & $0 \mathrm{a}$ & $0 \mathrm{a}$ & $0 \mathrm{a}$ & $7 \mathrm{a}$ & $0 \mathrm{a}$ & $9 \mathrm{a}$ & $0 \mathrm{a}$ & $0 \mathrm{a}$ & $24 \mathrm{a}$ & $0 \mathrm{a}$ & $0 \mathrm{a}$ & 47 \\
\hline \multirow{2}{*}{ Sthilosanthes sp. } & 12 & $0 \mathrm{a}$ & $0 \mathrm{~b}$ & $0 \mathrm{a}$ & $0 \mathrm{a}$ & $0 \mathrm{a}$ & $0 \mathrm{a}$ & $0 \mathrm{a}$ & $0 \mathrm{a}$ & $0 \mathrm{a}$ & $0 \mathrm{a}$ & $0 \mathrm{a}$ & $0 \mathrm{a}$ & $0 \mathrm{a}$ & $0 \mathrm{a}$ & 0 \\
\hline & 28 & $0 \mathrm{a}$ & $17.5 \mathrm{a}$ & $0 \mathrm{a}$ & $0 \mathrm{a}$ & $0 \mathrm{a}$ & $0 \mathrm{a}$ & $0 \mathrm{a}$ & $0 \mathrm{a}$ & $10.5 \mathrm{a}$ & $0 \mathrm{a}$ & $0 \mathrm{a}$ & $0 \mathrm{a}$ & $0 \mathrm{a}$ & $0 \mathrm{a}$ & 0 \\
\hline
\end{tabular}

An: Aspergillus niger; As: Aspergillus sp.; Bi: Bipolaris sp.; Bo: Botrytis sp.; Ch: Chaetomium sp.; Cu: Curvularia sp.; Fu: Fusarium sp.; He: Helminthosporium sp.; Pe: Penicillium sp.; Ph: Phoma sp.; Pi: Pithomyces sp.; Rh: Rhizophus sp.; Sc: Sclerotium sp.; Tr: Trichoderma sp.

Measures followed by the same letter in the column, among forage plants, do not differ inwardly by Tukey's test $(\mathrm{p}<0.05)$. 
Table 5. Incidence of fungi in tropical forage plant seeds, with disinfestation of tegument.

\begin{tabular}{|c|c|c|c|c|c|c|c|c|c|c|c|c|c|c|c|c|}
\hline \multirow{2}{*}{ Forage } & \multirow{2}{*}{ Lot } & \multicolumn{14}{|c|}{ Incidence of Fungi (\%) } & \multirow{2}{*}{ Tota } \\
\hline & & An & As & $\mathrm{Bi}$ & Bo & $\mathrm{Ch}$ & $\mathrm{Cu}$ & $\mathrm{Fu}$ & $\mathrm{He}$ & $\mathrm{Pe}$ & $\mathrm{Ph}$ & $\mathrm{Pi}$ & $\mathrm{Rh}$ & $\mathrm{Sc}$ & $\operatorname{Tr}$ & \\
\hline \multirow{2}{*}{ B. brizantha } & 16 & $0 \mathrm{a}$ & $0 \mathrm{a}$ & $1 \mathrm{a}$ & $0 \mathrm{a}$ & $1 \mathrm{a}$ & $0 \mathrm{a}$ & 1a & $0 \mathrm{a}$ & $0 \mathrm{a}$ & $2 \mathrm{a}$ & $0 \mathrm{a}$ & $0 \mathrm{a}$ & $3 a$ & $0 \mathrm{a}$ & 8 \\
\hline & 15 & $0 \mathrm{a}$ & $0 \mathrm{a}$ & $0 \mathrm{a}$ & $0 \mathrm{a}$ & $1 \mathrm{a}$ & $1 \mathrm{a}$ & $1 \mathrm{a}$ & $0 \mathrm{a}$ & $2 \mathrm{a}$ & $1 \mathrm{a}$ & $1 \mathrm{a}$ & $1 \mathrm{a}$ & $1 \mathrm{a}$ & $0 \mathrm{a}$ & 9 \\
\hline \multirow{6}{*}{ B. brizantha Marandu } & 1 & $0 \mathrm{a}$ & $0 \mathrm{a}$ & $0 \mathrm{a}$ & $0 \mathrm{a}$ & $0 \mathrm{a}$ & $0 \mathrm{a}$ & $1 \mathrm{a}$ & $0 \mathrm{a}$ & $0 \mathrm{a}$ & $0 \mathrm{a}$ & $0 \mathrm{a}$ & $0 \mathrm{a}$ & $5 a$ & $1 \mathrm{a}$ & 7 \\
\hline & 21 & 0a & $0 \mathrm{a}$ & $0 \mathrm{a}$ & $0 \mathrm{a}$ & $0 \mathrm{a}$ & $0 \mathrm{a}$ & $0 \mathrm{a}$ & 0a & $0 \mathrm{a}$ & $0 \mathrm{a}$ & $0 \mathrm{a}$ & $0 \mathrm{a}$ & $0 \mathrm{a}$ & $0 \mathrm{a}$ & 0 \\
\hline & 2 & $0 \mathrm{a}$ & $5 a$ & $1 \mathrm{a}$ & $0 \mathrm{a}$ & $0 \mathrm{a}$ & $2 \mathrm{a}$ & $0 \mathrm{a}$ & $0 \mathrm{a}$ & $0 \mathrm{a}$ & $1 \mathrm{a}$ & $0 \mathrm{a}$ & $0 \mathrm{a}$ & $1 \mathrm{a}$ & $0 \mathrm{a}$ & 10 \\
\hline & 3 & $0 \mathrm{a}$ & $0 \mathrm{a}$ & $0 \mathrm{a}$ & $0 \mathrm{a}$ & $0 \mathrm{a}$ & $0 \mathrm{a}$ & $0 \mathrm{a}$ & $0 \mathrm{a}$ & $0 \mathrm{a}$ & $0 \mathrm{a}$ & $0 \mathrm{a}$ & $0 \mathrm{a}$ & $0 \mathrm{a}$ & $0 \mathrm{a}$ & 0 \\
\hline & 4 & $1 \mathrm{a}$ & $1 \mathrm{a}$ & $2 \mathrm{a}$ & $1 \mathrm{a}$ & $0 \mathrm{a}$ & $1 \mathrm{a}$ & $0 \mathrm{a}$ & $0 \mathrm{a}$ & $0 \mathrm{a}$ & $2 \mathrm{a}$ & $0 \mathrm{a}$ & $1 \mathrm{a}$ & $0 \mathrm{a}$ & $0 \mathrm{a}$ & 9 \\
\hline & 5 & $0 \mathrm{a}$ & $0 \mathrm{a}$ & $0 \mathrm{a}$ & $0 \mathrm{a}$ & $1 \mathrm{a}$ & $2 \mathrm{a}$ & $1 \mathrm{a}$ & $0 \mathrm{a}$ & $0 \mathrm{a}$ & $1 \mathrm{a}$ & $0 \mathrm{a}$ & $0 \mathrm{a}$ & $3 a$ & $0 \mathrm{a}$ & 8 \\
\hline \multirow{2}{*}{ B. brizantha MG5 } & 19 & $0 \mathrm{a}$ & $1 \mathrm{a}$ & $0 \mathrm{a}$ & $0 \mathrm{a}$ & $3 a$ & $0 \mathrm{a}$ & $0 \mathrm{a}$ & $0 \mathrm{a}$ & $2 \mathrm{a}$ & $3 a$ & $0 \mathrm{a}$ & $0 \mathrm{a}$ & 1a & $0 \mathrm{a}$ & 14 \\
\hline & 25 & $0 \mathrm{a}$ & $1 \mathrm{a}$ & $1 \mathrm{a}$ & $0 \mathrm{a}$ & $4 a$ & $0 \mathrm{a}$ & $0 \mathrm{a}$ & $0 \mathrm{a}$ & $0 \mathrm{a}$ & $0 \mathrm{a}$ & $0 \mathrm{a}$ & $0 \mathrm{a}$ & $1 \mathrm{a}$ & $0 \mathrm{a}$ & 7 \\
\hline \multirow{2}{*}{ B. brizantha Piatã } & 18 & $0 \mathrm{a}$ & $0 \mathrm{a}$ & $1 \mathrm{a}$ & $0 \mathrm{a}$ & $0 \mathrm{a}$ & $1 \mathrm{a}$ & $1 \mathrm{a}$ & $0 \mathrm{a}$ & $0 \mathrm{a}$ & $3 a$ & $0 \mathrm{a}$ & $0 \mathrm{a}$ & $4 a$ & $0 \mathrm{a}$ & 10 \\
\hline & 24 & $0 \mathrm{a}$ & $0 \mathrm{a}$ & $3 \mathrm{a}$ & $0 \mathrm{a}$ & $0 \mathrm{a}$ & $0 \mathrm{a}$ & $0 \mathrm{a}$ & $0 \mathrm{a}$ & $0 \mathrm{a}$ & $1 \mathrm{a}$ & $0 \mathrm{a}$ & $0 \mathrm{a}$ & $0 \mathrm{~b}$ & $0 \mathrm{a}$ & 4 \\
\hline \multirow{2}{*}{ B. decumbens Basilisk } & 6 & $0 \mathrm{a}$ & $3 a$ & $1 \mathrm{a}$ & 1a & $0 \mathrm{a}$ & 1a & $0 \mathrm{a}$ & $0 \mathrm{a}$ & $0 \mathrm{a}$ & $4 a$ & $0 \mathrm{a}$ & $0 \mathrm{a}$ & $0 \mathrm{a}$ & $0 \mathrm{a}$ & 10 \\
\hline & 7 & $0 \mathrm{a}$ & $0 \mathrm{a}$ & $0 \mathrm{a}$ & $0 \mathrm{a}$ & $0 \mathrm{a}$ & $0 \mathrm{a}$ & $1 \mathrm{a}$ & $0 \mathrm{a}$ & $0 \mathrm{a}$ & $1 \mathrm{a}$ & $0 \mathrm{a}$ & $0 \mathrm{a}$ & $0 \mathrm{a}$ & $0 \mathrm{a}$ & 2 \\
\hline \multirow{3}{*}{ B. humidicola } & 20 & $0 \mathrm{a}$ & $0 \mathrm{a}$ & $0 \mathrm{a}$ & $0 \mathrm{a}$ & $0 \mathrm{a}$ & $0 \mathrm{a}$ & 1a & $0 \mathrm{a}$ & $0 \mathrm{a}$ & $0 \mathrm{a}$ & $0 \mathrm{a}$ & $0 \mathrm{a}$ & $0 \mathrm{a}$ & $0 \mathrm{a}$ & 1 \\
\hline & 8 & $0 \mathrm{a}$ & $0 \mathrm{a}$ & $0 \mathrm{a}$ & $0 \mathrm{a}$ & $0 \mathrm{a}$ & $1 \mathrm{a}$ & $0 \mathrm{a}$ & $0 \mathrm{a}$ & $0 \mathrm{a}$ & $0 \mathrm{a}$ & $0 \mathrm{a}$ & $0 \mathrm{a}$ & $0 \mathrm{a}$ & $0 \mathrm{a}$ & 1 \\
\hline & 17 & $0 \mathrm{a}$ & $0 \mathrm{a}$ & $0 \mathrm{a}$ & $0 \mathrm{a}$ & $0 \mathrm{a}$ & $1 \mathrm{a}$ & $0 \mathrm{a}$ & $0 \mathrm{a}$ & $0 \mathrm{a}$ & $0 \mathrm{a}$ & $0 \mathrm{a}$ & $1 \mathrm{a}$ & $0 \mathrm{a}$ & $0 \mathrm{a}$ & 2 \\
\hline \multirow{2}{*}{ B. ruziziensis } & 9 & $0 \mathrm{a}$ & $0 \mathrm{a}$ & $0 \mathrm{a}$ & $0 \mathrm{a}$ & $0 \mathrm{a}$ & 1a & $0 \mathrm{a}$ & $0 \mathrm{a}$ & $0 \mathrm{a}$ & $0 \mathrm{a}$ & $0 \mathrm{a}$ & $0 \mathrm{a}$ & $0 \mathrm{a}$ & $0 \mathrm{a}$ & 1 \\
\hline & 10 & 0a & 0a & $0 \mathrm{a}$ & $0 \mathrm{a}$ & $0 \mathrm{a}$ & $0 \mathrm{~b}$ & $0 \mathrm{a}$ & 0a & $0 \mathrm{a}$ & $0 \mathrm{a}$ & 0a & $0 \mathrm{a}$ & 0a & $0 \mathrm{a}$ & 0 \\
\hline \multirow{2}{*}{ C. juncea } & 22 & $0 \mathrm{a}$ & $0 \mathrm{a}$ & $0 \mathrm{a}$ & $0 \mathrm{a}$ & $0 \mathrm{a}$ & $0 \mathrm{a}$ & $0 \mathrm{a}$ & $0 \mathrm{a}$ & $0 \mathrm{a}$ & $0 \mathrm{a}$ & $0 \mathrm{a}$ & $0 \mathrm{a}$ & $0 \mathrm{a}$ & $0 \mathrm{a}$ & 0 \\
\hline & 26 & $0 \mathrm{a}$ & $0 \mathrm{a}$ & $0 \mathrm{a}$ & $0 \mathrm{a}$ & $0 \mathrm{a}$ & $0 \mathrm{a}$ & $0 \mathrm{a}$ & $0 \mathrm{a}$ & $0 \mathrm{a}$ & $0 \mathrm{a}$ & $0 \mathrm{a}$ & $0 \mathrm{a}$ & $0 \mathrm{a}$ & $0 \mathrm{a}$ & 0 \\
\hline \multirow{2}{*}{ P. maximum Mombaça } & 23 & 0a & $0 \mathrm{a}$ & $0 \mathrm{a}$ & $0 \mathrm{a}$ & $0 \mathrm{a}$ & $0 \mathrm{a}$ & $1 \mathrm{a}$ & $0 \mathrm{a}$ & $0 \mathrm{a}$ & $0 \mathrm{a}$ & $0 \mathrm{a}$ & $0 \mathrm{a}$ & $0 \mathrm{a}$ & $0 \mathrm{a}$ & 1 \\
\hline & 27 & $0 \mathrm{a}$ & $0 \mathrm{a}$ & $2 a$ & $0 \mathrm{a}$ & $0 \mathrm{a}$ & $2 \mathrm{a}$ & $2 a$ & $0 \mathrm{a}$ & $0 \mathrm{a}$ & $1 \mathrm{a}$ & $0 \mathrm{a}$ & $0 \mathrm{a}$ & $0 \mathrm{a}$ & $0 \mathrm{a}$ & 7 \\
\hline \multirow{3}{*}{ P. maximum Massai } & 11 & $0 \mathrm{a}$ & $0 \mathrm{a}$ & 1a & $0 \mathrm{a}$ & $0 \mathrm{a}$ & $1 \mathrm{a}$ & $1 \mathrm{a}$ & $0 \mathrm{a}$ & $0 \mathrm{a}$ & $0 \mathrm{a}$ & $0 \mathrm{a}$ & $0 \mathrm{a}$ & $0 \mathrm{a}$ & $0 \mathrm{a}$ & 3 \\
\hline & 13 & $0 \mathrm{a}$ & $3 a$ & $1 \mathrm{a}$ & $0 \mathrm{a}$ & $0 \mathrm{a}$ & $1 \mathrm{a}$ & $1 \mathrm{a}$ & $0 \mathrm{a}$ & $2 a$ & $0 \mathrm{a}$ & $0 \mathrm{a}$ & $0 \mathrm{a}$ & $0 \mathrm{a}$ & $0 \mathrm{a}$ & 8 \\
\hline & 14 & $0 \mathrm{a}$ & $0 \mathrm{a}$ & $1 \mathrm{a}$ & $0 \mathrm{a}$ & $0 \mathrm{a}$ & 1a & $0 \mathrm{a}$ & $0 \mathrm{a}$ & $0 \mathrm{a}$ & $0 \mathrm{a}$ & $0 \mathrm{a}$ & $0 \mathrm{a}$ & $0 \mathrm{a}$ & $0 \mathrm{a}$ & 2 \\
\hline \multirow{2}{*}{ Sthilosanthes sp. } & 12 & $0 \mathrm{a}$ & $0 \mathrm{a}$ & $0 \mathrm{a}$ & $0 \mathrm{a}$ & $0 \mathrm{a}$ & $0 \mathrm{a}$ & $0 \mathrm{a}$ & $0 \mathrm{a}$ & $0 \mathrm{a}$ & $0 \mathrm{a}$ & $0 \mathrm{a}$ & $0 \mathrm{a}$ & $0 \mathrm{a}$ & $0 \mathrm{a}$ & 0 \\
\hline & 28 & $0 \mathrm{a}$ & $0 \mathrm{a}$ & $0 \mathrm{a}$ & $0 \mathrm{a}$ & $0 \mathrm{a}$ & $0 \mathrm{a}$ & $0 \mathrm{a}$ & $0 \mathrm{a}$ & $0 \mathrm{a}$ & $0 \mathrm{a}$ & $0 \mathrm{a}$ & $0 \mathrm{a}$ & 0a & $0 \mathrm{a}$ & 0 \\
\hline
\end{tabular}

An: Aspergillus niger; As: Aspergillus sp.; Bi: Bipolaris sp.; Bo: Botrytis sp.; Ch: Chaetomium sp.; Cu: Curvularia sp.; Fu: Fusarium sp.; He: Helminthosporium sp.; Pe: Penicillium sp.; Ph: Phoma sp.; Pi: Pithomyces sp.; Rh: Rhizophus sp.; Sc: Sclerotium sp.; Tr: Trichoderma sp.

Measures followed by the same letter in the column, among forage plants, do not differ inwardly by Tukey's test $(\mathrm{p}<0.05)$.

\section{Pathogenicity}

On the first assay, from a total of 28 lots tested, sixteen present seedlings emergence lower than $50 \%$ (Table 6), for lot 9 B. ruziziensis, the emergence percentage was zero. One of the causes may be the presence of fungi Fusarium sp. and Rhizopus sp. (Table 3), which may affect the viability of forage plant seeds (Marchi et al., 2010).

During the evaluations, after the seedling inoculations, leaf spots were detected in seedlings of three forage species: $B$. brizantha, $C$. juncea and $P$. maximum. The leaf spots presented characteristics of damages caused by Bipolaris sp. In general, other studies report the susceptibility of these grasses to attacks of fungi from genre Bipolaris, Exserohilum and Curvularia, which cause spots in leaves and stalks, besides drying the leaves and killing the seedlings (Macedo and Barreto, 2007; Martinez et al., 2010; Kleczewski et al., 2012; Braz et al., 2013; Kumar et al., 2013), however, some authors realized that this result may vary in accordance with the genotype used (Braz et al., 2013).

Yago et al. (2011) observed that there was an increase in the seedling death percentage for sorghum and foxtail millet seeds inoculated with Curvularia lunata and increase in the severity index for infected seedlings 10 days after the inoculation.

With re-isolation in culture media, there was presence of conidia of fungus Bipolaris sp., showing a crossed pathogenicity, since the inoculum applied was removed from other seed lots (Table 7).

As seen in Table 8, the lots of Brachiaria that presented spots on the tegument had lower emergence percentage, staying under $50 \%$ in this treatment. Although not quantified in the transport assay, one explanation for this low germination percentage is that the Brachiaria seeds with dark (spotted) teguments had a larger incidence of potentially pathogenic fungi, which are capable of affecting the forage plant seeds germination, such as Bipolaris sp., Curvularia sp., Fusarium sp., Phoma sp. and Rhizophus sp. 
Table 6. Emergence (\%) of tropical forage plant seedlings sowed in commercial sterilized substrate, with disinfestation of tegument.

\begin{tabular}{|c|c|c|}
\hline Forage plant & Lot & Emergence (\%) \\
\hline \multirow{2}{*}{ B. brizantha } & 16 & 16 \\
\hline & 15 & 68 \\
\hline \multirow{2}{*}{ B. brizantha Marandu } & 18 & 36 \\
\hline & 24 & 28 \\
\hline \multirow{6}{*}{ B. brizantha MG5 } & 1 & 72 \\
\hline & 21 & 12 \\
\hline & 2 & 4 \\
\hline & 3 & 8 \\
\hline & 4 & 8 \\
\hline & 5 & 28 \\
\hline \multirow{2}{*}{ B. brizantha Piatã } & 19 & 84 \\
\hline & 25 & 68 \\
\hline \multirow{2}{*}{ B. decumbens Basilisk } & 6 & 84 \\
\hline & 7 & 48 \\
\hline \multirow{3}{*}{ B. humidicola } & 20 & 4 \\
\hline & 8 & 40 \\
\hline & 17 & 16 \\
\hline \multirow{2}{*}{ B. ruziziensis } & 9 & 0 \\
\hline & 10 & 8 \\
\hline \multirow{2}{*}{ C. juncea } & 22 & 16 \\
\hline & 26 & 28 \\
\hline \multirow{3}{*}{ P. maximum Mombaça } & 11 & 80 \\
\hline & 13 & 100 \\
\hline & 14 & 80 \\
\hline \multirow{2}{*}{ P. maximum Massai } & 23 & 76 \\
\hline & 27 & 28 \\
\hline \multirow{2}{*}{ Sthilosanthes sp. } & 12 & 100 \\
\hline & 28 & 94 \\
\hline
\end{tabular}

Table 7. Inoculation of eight Bipolaris sp. isolated in forage seedlings.

\begin{tabular}{cccccccccc}
\hline & \multicolumn{1}{c}{ Lot of origin of the } \\
Forage Species & Lot* & \multicolumn{7}{c}{ isolated/Pathogenicity** } \\
\cline { 2 - 10 } & & 2 & 7 & 10 & 11 & 15 & 17 & 18 & 19 \\
\hline \multirow{2}{*}{ B. brizantha } & 16 & - & - & - & - & - & + & + & + \\
& 15 & + & - & - & - & + & - & - & - \\
\hline B. brizantha & 18 & + & - & + & - & - & - & - & + \\
Piatã & 24 & - & + & + & + & - & + & + & - \\
\hline \multirow{2}{*}{ C. juncea } & 22 & + & - & - & - & - & - & + & - \\
& 26 & + & - & - & - & - & - & - & - \\
\hline \multirow{2}{*}{ P. maximum } & 11 & - & + & + & + & - & - & - & - \\
Massai & 13 & + & - & + & - & + & - & - & - \\
\hline P. maximum & 14 & - & - & - & + & - & - & - & - \\
Mombaça & 23 & + & + & - & - & - & - & - & - \\
\hline
\end{tabular}

*Lot 2-B. brizantha Marandu. Lot 7-B. decumbens Basilisk. Lot 10-B. ruziziensis. Lot 11-P. maximum Massai. Lot 15-B. brizantha. Lot 17-B. humidicola. Lot 18-B. brizantha Piatã and Lot 19-B. brizantha MG5. ** + isolated pathogenic species - non pathogenic isolated species.
Table 8. Percentage of Brachiaria spp. seedlings emergence sowed without disinfestation of tegument in sterilized sand, with separation of seeds with spots in the tegument (CMT) and seeds without spots in the tegument (SMT).

\begin{tabular}{|c|c|c|c|}
\hline \multirow{2}{*}{ Forage plant } & \multirow{2}{*}{ Lot } & \multicolumn{2}{|c|}{ Emergence (\%) } \\
\hline & & CMT & SMT \\
\hline \multirow{2}{*}{ B. brizantha } & 16 & 16 & 24 \\
\hline & 15 & 4 & 55 \\
\hline \multirow{2}{*}{ B. brizantha Piatã } & 18 & 2 & 27 \\
\hline & 24 & 16 & 28 \\
\hline \multirow{6}{*}{$\begin{array}{l}\text { B. brizantha } \\
\text { Marandu }\end{array}$} & 1 & 16 & 53 \\
\hline & 21 & 0 & 44 \\
\hline & 2 & 2 & 6 \\
\hline & 3 & 4 & 4 \\
\hline & 4 & 10 & 32 \\
\hline & 5 & 12 & 8 \\
\hline \multirow{2}{*}{ B. brizantha MG5 } & 19 & 23 & 60 \\
\hline & 25 & 0 & 44 \\
\hline B. decumbens & 6 & 12 & 80 \\
\hline Basilisk & 7 & 9 & 9 \\
\hline \multirow{3}{*}{ B. humidicola } & 20 & 20 & 18 \\
\hline & 8 & 16 & 3 \\
\hline & 17 & 0 & 12 \\
\hline \multirow{2}{*}{ B. ruziziensis } & 9 & 0 & 0 \\
\hline & 10 & 1 & 3 \\
\hline Mean & & $8.57 \mathrm{~b}$ & $26.84 a$ \\
\hline
\end{tabular}

Measures followed by the same letter in the column do not differ inwardly by Tukey's test $(\mathrm{p}<0.05)$.

Dias and Toledo (1993) noted that the increase in the incidence of fungi Curvularia and Phoma in seeds of $B$. decumbens corresponded to decrease in the seeds germination percentage, while Lasca et al. (2004) saw that these fungi, when present on the seeds of forage species, affected the emergence of seedlings and provoked their death.

\section{Seed-seedling transmission}

The seed-seedling transmission was confirmed to Bipolaris sp. and Curvularia sp. as shown in Table 9. The incidence of Bipolaris sp. and Curvularia sp. in the seeds varied from 0 to $16 \%$ and from 0 to $22 \%$ respectively, as seen in Table 4 . However, the absence or the reduced incidence in some lots has not reflected a lower transmission of these fungi that are pathogenic to the forage plant seedlings evaluated (Table 9).

Fungus Curvularia was identified by Lasca et al. (2004) being transmitted by Brachiaria seeds and causing leaf spots in seedlings of this forage plant.

Medina et al. (2009) observed lack of effects resultant from the incidence of Curvularia lunata (0.5 to $1.5 \%)$ and Phoma spp. (0.5 to $4.0 \%)$ in the X. triticosecale Wittmack seed germination and in the transmission of these pathogenic 
elements to the seedlings. These authors believe, however, that infected seeds play an important role in the epidemiology of diseases caused by these pathogenic elements, due to the introduction of inoculum sources in agriculture since the early stages of the plants.

Table 9. Incidence of Bipolaris sp. and Curvularia sp. transmitted via seed-seedling.

\begin{tabular}{|c|c|c|c|c|}
\hline \multirow[b]{2}{*}{ Forage Species } & \multirow[b]{2}{*}{ Lot } & \multirow{2}{*}{$\begin{array}{c}\text { Emergence } \\
(\%)\end{array}$} & \multicolumn{2}{|c|}{ Incidence $(\%)$} \\
\hline & & & $\begin{array}{c}\text { Bipolaris } \\
\text { sp. }\end{array}$ & $\begin{array}{c}\text { Curvularia } \\
\text { sp. }\end{array}$ \\
\hline \multirow{2}{*}{ B. brizantha } & 16 & 20 & 7 & 3 \\
\hline & 15 & 23 & 13 & 4 \\
\hline \multirow{2}{*}{$\begin{array}{l}\text { B. brizantha } \\
\text { Marandu }\end{array}$} & 18 & 30 & 0 & 0 \\
\hline & 24 & 22 & 0 & 0 \\
\hline \multirow{6}{*}{$\begin{array}{l}\text { B. brizantha } \\
\text { MG5 }\end{array}$} & 1 & 90 & 0 & 0 \\
\hline & 21 & 22 & 31 & 0 \\
\hline & 2 & 9 & 30 & 0 \\
\hline & 3 & 8 & 0 & 0 \\
\hline & 4 & 10 & 0 & 0 \\
\hline & 5 & 33 & 0 & 0 \\
\hline \multirow{2}{*}{$\begin{array}{l}\text { B. brizantha } \\
\text { Piatã }\end{array}$} & 19 & 92 & 57 & 0 \\
\hline & 25 & 50 & 0 & 30 \\
\hline \multirow{2}{*}{$\begin{array}{l}\text { B. decumbens } \\
\text { Basilisk }\end{array}$} & 6 & 77 & 0 & 0 \\
\hline & 7 & 50 & 22 & 0 \\
\hline \multirow{3}{*}{ B. humidicola } & 20 & 9 & 0 & 15 \\
\hline & 8 & 42 & 0 & 0 \\
\hline & 17 & 19 & 0 & 0 \\
\hline \multirow{2}{*}{ B. ruziziensis } & 9 & 0 & 0 & 0 \\
\hline & 10 & 16 & 15 & 0 \\
\hline \multirow{2}{*}{ C. juncea } & 22 & 16 & 0 & 39 \\
\hline & 26 & 32 & 0 & 2 \\
\hline \multirow{3}{*}{$\begin{array}{l}\text { P. maximum } \\
\text { Massai }\end{array}$} & 11 & 65 & 0 & 0 \\
\hline & 13 & 100 & 0 & 24 \\
\hline & 14 & 85 & 0 & 7 \\
\hline \multirow{2}{*}{$\begin{array}{l}\text { P. maximum } \\
\text { Mombaça }\end{array}$} & 23 & 64 & 0 & 0 \\
\hline & 27 & 37 & 0 & 0 \\
\hline \multirow{2}{*}{ Sthilosanthes sp. } & 12 & 100 & 0 & 0 \\
\hline & 28 & 98 & 0 & 0 \\
\hline
\end{tabular}

Medeiros et al. (2012) observed that the high incidence of fungi in Caesalpinia pulcherrima seeds increased the transmission of the pathogenic elements to seedlings of this species.

In some seed lots there was no seed-seedling transmission; the seeds germinated, produced seedlings with no symptoms of diseases. Yet, these seedlings may produce low quality seeds with tegument tissue infested by the identified pathogenic elements, being, thus, transported, because the transmission can be influenced by several factors.

Some factors that influence the transmission of a pathogenic element by the seed are: cultivated species (varietal resistance), environment conditions (environment and soil humidity, temperature, wind, rain and light), inoculums (viability, location in the seed, type), culture practices (soil type, $\mathrm{pH}$, plant population, sowing depth and planting season, fertilization), inoculums survival, soil and seed microflora, among others (Barba et al., 2002).

\section{Conclusions}

The fungus Bipolaris sp. is prejudicial to forage plant seedling of the genres Brachiaria, Crotalaria and Panicum.

Bipolaris sp. and Curvularia sp. are transmitted from seeds to seedlings.

\section{References}

ANJOS, J.R.N.; CHARCHAR, M.J.A.; TEIXEIRA, R.N.; ANJOS, S.S.N. Ocorrência de Bipolaris maydis causando mancha foliar em Paspalum atratum cv. Pojuca no Brasil. Fitopatologia Brasileira, v.29, n.6, p.656-658, 2004. http://www.scielo.br/pdf/fb/v29n6/a10v29n6.pdf

BARBA, J.T.; REIS, E.M.; FORCELINI, C.A. Efeito da temperatura e de fungicida na transmissão de Bipolaris sorokiniana da semente para plântulas de cevada. Fitopatologia Brasileira, v.27, n.5, p.500-507, 2002. http://www. scielo.br/pdf/fb/v27n5/14058.pdf

BARNETT, H.C.; HUNTER, B.B. Illustrated genera of imperfect fungi. 3. ed. Mineapolis: Burgess Publishing, 1972. 241 p.

BRASIL. Ministério da Agricultura, Pecuária e Abastecimento. Regras para análise de sementes. Ministério da Agricultura, Pecuária e Abastecimento. Secretaria de Defesa Agropecuária. Brasília: MAPA/ACS, 2009a. 395 p. http://www.bs.cca.ufsc.br/publicacoes/regras\%20analise\%20sementes.pdf

BRASIL. Instrução normativa ${ }^{\circ} 9$, de 02 de junho de 2005. Diário Oficial da República Federativa do Brasil, Poder Executivo, Brasília, DF, 10 jun. 2005. Seção I, p.4. http://www.jusbrasil.com.br/diarios/646762/pg-4-secao1-diario-oficial-da-uniao-dou-de-10-06-2005

BRASIL. Instrução normativa $\mathrm{n}^{\circ} 45$, de 17 de setembro de 2013. Diário Oficial da República Federativa do Brasil, Poder Executivo, Brasília, DF, 20 set. 2013. Seção I, p.6. http://www.jusbrasil.com.br/diarios/59354724/dousecao-1-20-09-2013-pg-6

BRAZ, T.G.S.; FONSECA, D.M.; JANK, L.; RESENDE, M.D.V.; MARTUSCELLO, J.A.; SIMEÃO, R.M. Genetic parameters of agronomic characters in Panicum maximum hybrids. Revista Brasileira de Zootecnia, v. 42 , n. 4 , p.231-237, 2013. http://www.scielo.br/scielo.php?script=sci pdf\&pid=S151635982013000400001\&lng=en\&nrm=iso\&tlng=en

CAMERA, J.N.; DEUNER, C.C.; REIS, E.M.; RANZI, C. Limiares térmicos para a germinação de conídios de Cercospora sojina em dois regimes luminosos. Summa Phytopathologica, v.39, n.1, p.58-61, 2013. http://www. scielo.br/pdf/sp/v39n1/a10v39n1.pdf

CARVALHO, D.D.C.; MELLO, S.C.M.; LOBO JÚNIOR, M.; SILVA, M.C. Controle de Fusarium oxysporum $f$. sp. phaseoli in vitro e em sementes, e promoção de crescimento inicial do feijoeiro comum por Trichoderma harzianum. Tropical Plant Pathology, v.36, n.1, p.28-34, 2011. http://www. scielo.br/pdf/tpp/v36n1/a04v36n1.pdf 
DEMINICIS, B.B.; VIEIRA, H.D.; SILVA, R.F.; ABREU, J.B.R.; ARAÚJO, S.A.C.; JARDIM, J.G. Adubação nitrogenada, potássica e fosfatada na produção e germinação de sementes de capim quicuio-da-Amazônia. Revista Brasileira de Sementes, v.32, n.2, p.59-65, 2010. http://www.scielo.br/pdf/ $\mathrm{rbs} / \mathrm{v} 32 \mathrm{n} 2 / \mathrm{v} 32 \mathrm{n} 2 \mathrm{a} 07 . \mathrm{pdf}$

DIAS, D.C.F.S.; TOLEDO, F.F. Germinação e incidência de fungos em testes com sementes de Brachiaria decumbens STAPF. Revista Brasileira de Sementes, v.15, n.1, p.81-86, 1993.

DUARTE, M.L.R.; ALBUQUERQUE, F.C.; SANHUEZA, R.M.V.; VERZIGNASSI, J.R.; KONDO, N. Etiologia da podridão do coleto de Brachiaria brizantha em pastagens da Amazônia. Fitopatologia Brasileira, v.32, n.3 p.261-265, 2007. http://www.scielo.br/scielo.php?script=sci_ pdf\&pid=S0100-41582007000300013\&lng=pt\&nrm=iso\&tlng=pt

FERRAZ, J.B.S.; FELICIO, P.E.D. Production systems - an example from Brazil. Meat Science, v.84, n.2, p.238-243, 2010. http://www-sciencedirectcom.ez6.periodicos.capes.gov.br/science/article/pii/S0309174009001648/ pdfft? md5 $=63305476172 \mathrm{~d} 4 \mathrm{~b} 8 \mathrm{a} 26270 \mathrm{c} 18 \mathrm{ad} 902 \mathrm{db} 7 \& \mathrm{pid}=1-\mathrm{s} 2.0$ S0309174009001648-main.pdf

GAMA, J.S.N.; BRUNO, R.L.A.; SILVA, K.R.G.; RÊGO, E.R.; PEREIRA FILHO, T.B.; BARBOSA, R.C.; BEZERRA, A.K.D. Qualidade fisiológica e sanitária de sementes de erva-doce (Foeniculum vulgare Mill.) armazenadas. Revista Brasileira de Plantas Medicinais, v.14, n. espe, p.175-182, 2012. http:// www.scielo.br/scielo.php?pid=S1516-05722012000500009\&script=sci_arttext

KLECZEWSKI, N.M.; FLORY, S.L.; CLAY, K. Variation in pathogenicity and host range of Bipolaris sp. causing leaf blight disease on the invasive grass Microstegium vimineum. Weed Science, v.60, n.3, p.486-493, 2012. http://www.bioone.org/doi/full/10.1614/WS-D-11-00187.1\#.UhKII5K2OaU

KUMAR, A.C.K.; NAGARAJA, A.; RAGHAVENDRA, B.T.; RAVIKUMARA, B.M. Evaluation of fungicides against Drechslera setariae causing brown leaf spot of foxtail millet Setaria italica (L.). Environment and Ecology, v.31, n.2, p.801-803, 2013. http://www.cabi.org/cabdirect/FullTextPDF/2013/20133255912.pdf

LACERDA, A.L.C.; LAZARINI, E.; SÁ, M.E.; VALÉRIO FILHO, W.V. Armazenamento de sementes de soja dessecadas e avaliação da qualidade fisiológica, bioquímica e sanitária. Revista Brasileira de Sementes, v.25, n.2, p.97-105, 2003. http://www.scielo.br/scielo.php?script=sci arttext\&pid=S0101-31222003000400014

LASCA, C.C.; VECHIATO, M.H.; KOHARA, E.Y. Controle de fungos de sementes de Brachiaria spp.: eficiência de fungicidas e influência do período de armazenamento de sementes tratadas sobre a ação desses produtos. Arquivos do Instituto Biológico, v.71, n.4, p.465-472, 2004. http://www. biologico.sp.gov.br/docs/arq/V71_4/lasca.PDF

LAZAROTTO, M.; MUNIZ, M.F.B.; SANTOS, A.F. Detecção, transmissão, patogenicidade e controle químico de fungos em sementes de paineira (Ceiba speciosa). Summa Phytopathologica, v.36, n.2, p.134-139, 2010. http://www. scielo.br/scielo.php?pid=S0100-54052010000200005\&script=sci_arttext

MACEDO, D.M.; BARRETO, R.W. First report of leaf blight of Brachiaria brizantha in Brazil caused by Bipolaris cynodontis. Plant Pathology, v.56, n.6, p.1041, 2007. http://onlinelibrary.wiley.com/doi/10.1111/j.13653059.2007.01632.x/full
MARCHI, C.E.; FERNANDES, C.D.; BUENO, M.L.; BATISTA, M.V.; FABRIS, L.R. Microflora fúngica de sementes comerciais de Panicum maximum e Stylosanthes spp. Semina: Ciências Agrárias, v.31, n.3, p.575584, 2010. http://www.uel.br/revistas/uel/index.php/semagrarias/article/ view/6499/59055

MARTINEZ, A.S.; FRANZENER, G.; STANGARLIN, J.R . Dano causado por Bipolaris maydis em Panicum maximum cv. Tanzânia. Semina: Ciências Agrárias, v.31, n.4, p.863-870, 2010. http://www.uel.br/revistas/uel/index. php/semagrarias/article/view/2213/0

MEDEIROS, J.G.F.; SILVA, B.B.; NETO, A.C.A.; NASCIMENTO, L.C. Fungos associados com sementes de flamboyant-mirim (Caesalpinia pulcherrima): incidência, efeito na germinação, transmissão e controle. Pesquisa Florestal Brasileira, v.32, n.71, p.303-308, 2012. http://www.cnpf. embrapa.br/pfb/index.php/pfb/article/view/349

MEDINA, P.F.; TANAKA, M.A.S.; PARISI, J.J.D. Sobrevivência de fungos associados ao potencial fisiológico de sementes de triticale ( $X$. triticosecale Wittmack) durante o armazenamento. Revista Brasileira de Sementes, v.31, n.4, p.17-26, 2009. http://www.scielo.br/scielo.php?pid=S0101$31222009000400002 \&$ script $=$ sci_arttext

QUADROS, D.G.; ANDRADE, A.P.; OLIVEIRA, G.C.; OLIVEIRA, E.P.; MOSCON, E.S. Componentes da produção e qualidade de sementes dos cultivares marandu e xaraés de Brachiaria brizantha (Hochst. ex A. Rich.). Semina: Ciências Agrárias, v.33, n.5, p.2019-2028, 2012. http://www.uel.br/ revistas/uel/index.php/semagrarias/article/view/97122

SÁ, D.A.C.; SANTOS, G.R.; FURTADO, G.Q.; ERASMO, E.A.L.; NASCIMENTO, I.R. Transporte, patogenicidade e transmissibilidade de fungos associados às sementes de pinhão manso. Revista Brasileira de Sementes, v.33, n.4, p.663-670, 2011. http://www.scielo.br/pdf/rbs/v33n4/08.pdf

SENHOR, R.F.; SOUZA, P.A.; ANDRADE NETO, R.C.; PINTO, A.C.; SOARES, S.R.F. Colapso do meloeiro associado a Monosporascus cannonballus. Revista Verde, v.4, n.2, p.06-14, 2009. http://gvaa.com.br/ revista/index.php/RVADS/article/view/162/162

SILVA, G.M.; MAIA, M.S.; MORAES, C.O.C.; MEDEIROS, R.B.; SILVA, C.S.; PEREIRA, D.D. Fungos associados a sementes de ceva dilha vacariana (Bromus auleticus) coletadas nas plantas e no solo. Fitopatologia Brasileira, v.32, n.4, p.353-357, 2007. http://www.scielo.br/pdf/fb/v32n4/12.pdf

VECHIATO, M.H.; APARECIDO, C.C.; FERNANDES, C.D. Frequência de fungos em lotes de sementes comercializadas de Brachiaria e Panicum. Documento Técnico, n.4. 2010. Disponível em: <http://www.biologico. sp.gov.br/docs/dt/DT_07_2010.pdf $>$ Accessed on: Mar. 15 $5^{\text {th }} .2013$.

VERZIGNASSI, J.R.; POLTRONIERI, L.S.; BENCHIMOL, R.L.; FRANÇA, S.K.S.; CARVALHO, E.A.; FERNANDES, C.D. Pyricularia grisea: novo patógeno em Brachiaria brizantha cv. Marandu no Pará. Summa Phytopathologica, v.38, n.3, p.254, 2012.http://www.scielo.br/scielo.php?script=sci_pdf\&pid=S0100$54052012000300016 \& \operatorname{lng}=$ pt\&nrm=iso\&tlng=pt

YAGO, J.I.; ROH, J.H.; BAE, S.D.; YOON, Y.N.; KIM, H.J.; NAM, M.H. The effect of seed-borne mycoflora from sorghum and foxtail millet seeds on germination and disease transmission. Mycobiology, v.39, n.3, p.206-218, 2011. http://www.ncbi.nlm.nih.gov/pmc/articles/PMC3385107/ 